\title{
Long-term follow-up of implantable cardioverter- defibrillators in children: Indications and outcomes
}

\author{
Joanna Kwiatkowska, 1 -D, , , Szymon Budrejk2,B, , , Marek Wasicionek, 3,B-D,F \\ Jarosław Meyer-Szary ${ }^{1, C, F}$, Andrzej Lubiński ${ }^{4, B, C, F}$, Maciej Kempa ${ }^{2, B, D-F}$ \\ ${ }^{1}$ Department of Pediatric Cardiology and Congenital Heart Defect, Medical University of Gdansk, Poland \\ ${ }^{2} 2^{\text {nd }}$ Department of Cardiology and Electrotherapy, Medical University of Gdansk, Poland \\ ${ }^{3} 1^{\text {st }}$ Department and Clinic of Pediatric, Allergology and Cardiology, Wroclaw Medical University, Poland \\ ${ }^{4}$ Department of Interventional Cardiology and Cardiac Arrhythmias, Medical University of Lodz, Poland \\ A - research concept and design; $\mathrm{B}$ - collection and/or assembly of data; $\mathrm{C}$ - data analysis and interpretation; \\ $D$ - writing the article; $E$ - critical revision of the article; $F$ - final approval of the article
}

\section{Address for correspondence}

Marek Wasicionek

E-mail:marek.wasicionek@umed.wroc.pl

Funding sources

None declared

Conflict of interest

None declared

Received on December 30, 2018

Reviewed on April 19, 2019

Accepted on June 27, 2019

Published online on December 30, 2019

Cite as

Kwiatkowska J, Budrejko Sz, Wasicionek M, Meyer-Szary J, Lubiński A, Kempa M. Long-term follow-up of implantable cardioverter-defibrillators in children: Indications and outcomes. Adv Clin Exp Med. 2020;29(1):123-133. doi:10.17219/acem/110313

DOI

10.17219/acem/110313

Copyright

Copyright by Author(s)

This is an article distributed under the terms of the

Creative Commons Attribution 3.0 Unported (CC BY 3.0)

(https://creativecommons.org/licenses/by/3.0/)

\begin{abstract}
Background. Validation data of the use of implantable cardioverter-defibrillators (ICD) in the pediatric population is insufficient, with limited follow-up periods.

Objectives. The aim of the study was to report on 17 years of experience with implantable cardioverterdefibrillator (ICD) therapy in children and young adults.

Material and methods. This retrospective review included patients below the age of 18 years at the time of ICD implantation between May 2000 and December 2017. For the statistical analysis, the sample was divided into groups by gender and the type of indications for ICD implantation (primary vs secondary prevention).

Results. The study group included 20 children (8 female, 12 male) who underwent ICD implantation for primary or secondary prevention of sudden cardiac death (SCD). The average age at the time of the initial procedure was 15.6 years (range: 3.8-17.7 years). Primary electrical disease (PED) was present in 9 patients, cardiomyopathy (CMP) in 9 and 2 others had congenital heart defects (CHDs). The median follow-up time was 6.7 years (range: $0.4-12.5$ years). The outcomes of ICD therapy were analyzed. No differences between the sexes were found in terms of treatment strategy effectiveness $(p>0.05)$. The girls were more often treated as primary prevention $(p=0.009)$. After implantation, all the patients were on optimal pharmacotherapy. Alltogether there were 126 ICD interventions in 11 patients, including 23 inadequate interventions (IA) in 2 children (18.2\%).Three children (15\%) died due to electrical storms. In the per-procedure analysis, the overall freedom rate from ICD lead replacement was $90 \%, 80 \%$ and $57 \%$ at 1,5 and 10 years of observation, respectively.
\end{abstract}

Conclusions. Implantable cardioverter-defibrillator implantation indications in children are more heterogeneous in comparison to adult population. In the pediatric population undergoing ICD implantation, the treatment strategy is influenced by gender. The rate of inappropriate ICD discharges $(I A)$ in our group of pediatric patients was low. Rigorous pharmacotherapy and individual ICD programming seemed of paramount importance. Lead malfunctions LF constituted the most prevalent complication observed.

Key words: sudden cardiac death, implantable cardioverter-defibrillator, pediatric cardiology 


\section{Introduction}

The authors present their own experience in the of use of implantable cardioverter-defibrillator (ICD) therapy in children, with one of the longest follow-up periods conducted in a single center from pediatrics to adulthood. Validation data for ICD use in pediatric populations is insufficient, with limited follow-up periods, and is primarily based on isolated clinical cases, single-center studies, registries, and a few comparison studies with ICD use in adults. Therefore, this paper is of high educational value to young scientists who at the beginning of their scientific and medical carrier need to deepen their medical knowledge and stay up-to-date with current guidelines and trends in medicine worldwide.

The implementation of ICD therapy has significantly decreased the number of sudden cardiac deaths (SCD) in the adult population. ${ }^{1-3}$ According to the American Heart Association (AHA) and American College of Cardiology (ACC) recommendations, the secondary prevention indications for ICD therapy are the same in children as in adults. The main indications for ICD implantation in the pediatric population are primary electrical heart disease (PED), cardiomyopathy (CMP), congenital heart defect (CHD) post-surgical correction, ventricular tachycardia (VT), and idiopathic ventricular fibrillation (VF) in patients with an anatomically normal heart. ${ }^{4,5}$

As there are no randomized pediatric ICD studies and because experience in the pediatric population is limited to small retrospective case series with short follow-up periods only, statistically significant results are difficult to obtain in this field. We hypothesized that single-center observations of a relatively large non-uniform pediatric group of patients with one of the longest-term follow-ups could contribute to better care of young patients.

The aim of the study was to analyze the indications for ICD implantation, programming issues and treatment options for any arrhythmic and device complications (failure rate and extractability of ICD leads implanted in patients below 18 years of age) in a follow-up period of up to 17 years, which in turn could also improve our understanding of the related issues.

\section{Material and methods}

The study was designed as a single-center retrospective analysis of all patients aged below 18 years who underwent ICD implantation between May 2000 and December 2017. The study was approved by the institutional review board and fully complies with the declaration of Helsinki (protocol No. NKBBN/7/2017).

Demographic information, diagnoses, indications for ICD implantation, age and weight at implantation, as well as device and lead information and the patients' course were collected. The indications for ICD implantation for SCD were established according to the guidelines and recommendations. ${ }^{4,6-8}$ Primary prevention indications were determined either according to the respective guidelines and recommendations or on an individual basis with special reference to the underlying cardiac condition. ${ }^{9-13}$ At the time of implantation, all the ICD systems were tested according to standard clinical practice and contemporary guidelines. ${ }^{14,15}$ Follow-up data included in-house follow-up as well as examinations by collaborating specialists. The patient follow-up started at the time of the $1^{\text {st }}$ implantation and lasted until death by any cause, or the date of the last documented device interrogation, or the end of the study in December 2017. The initial ICD check took place within the first days post implantation, after which follow-ups were performed at 4-6 weeks, 12 weeks and every 6 months thereafter, or more often if needed. Follow-up visits took place in the outpatient ICD clinic according to the standard protocol, and consisted of interrogation and retrieval of all data stored since the previous visit and routine measurements of pacing and sensing parameters. In addition, some patients were subject to remote monitoring of their ICD systems.

The follow-up data was evaluated for the presence of both appropriate (AI) and inappropriate shocks (IA), ICD programming information, any history of supraventricular tachycardia (SVT), and the use of antiarrhythmic (AA) medications. Inappropriate shocks were defined as shocks delivered for reasons other than VT or VF meeting programmed detection criteria. The details of the ICD programming were recorded at the time of either IA or the most recent followup visit if no IA occurred. The detection rate was recorded in beats per minute (bpm). The detection duration was recorded in either the number of beats or the number of seconds, depending on the device programming/manufacturer. For comparison purposes, detection duration in seconds was converted into duration in beats by using the programmed upper detection rate and the detection duration.

Ineffectiveness of the combined pharmacological therapy and ICD implantation was defined as no impact on the mortality rate in this specific pediatric group.

The technical outcome of ICD therapy was also analyzed retrospectively, and included lead malfunctions and complications. We identified implantation procedure complications and late follow-up complications as a composite of the following: mechanical complications caused by an ICD system, infection and inflammatory reaction due to the presence of the cardiac device or the implantation procedure, iatrogenic pneumothorax, accidental puncture or laceration, post-operative hemorrhage or hematoma, and other complications described in the literature.

\section{Statistical analysis}

Statistical analyses were performed using Wizard Pro v. 1.9.22 software (Evan Miller, Chicago, USA). Categorical variables were expressed as numbers (n) and percentages. Continuous variables were expressed as means \pm standard deviation (SD) or medians (minimum-maximum), 
depending on the distribution. The normality of distribution was tested using the Shapiro-Wilk test. The paired Student t-test and Wilcoxon signed-rank test were used for repeated measures, while the unpaired Student t-test and Mann-Whitney test were used for independent samples. For multiple comparisons, proper analysis of variance (ANOVA) or Friedman's test were used. Categorical data was compared using the $\chi^{2}$ test. A p-value $<0.05$ was considered significant for all tests.

For the statistical analysis, the sample was divided into groups by gender and the type of indications for ICD implantation (primary vs secondary prevention).

\section{Results}

\section{Patient characteristics/demographics}

The clinical and demographic characteristics of the study group, including indications for ICD implantation, are presented in Tables 1 and 2. Two patients moved to another town and are under cardiological follow-up in another center. The distribution of primary and secondary prevention indications and types of cardiovascular disease (CVD) in the study group are presented in detail in Fig. 1.

\section{Initial indications for ICD implantation}

The indication for ICD implantation was resuscitated sudden cardiac arrest (SCA) in 12 patients $(60 \%$, secondary prevention), while ICDs for primary prevention were implanted in 8 patients (40\%) (Table 2). The main symptoms leading to ICD implantation in the whole study group were transient loss of consciousness (TLOC) in 5 children (25\%) and palpitations in 2 (10\%). The other 13 patients (65\%) were asymptomatic. In 5 of the 7 symptomatic children echocardiographic (ECG) examinations revealed left ventricle ejection fraction (LVEF) below 20\% and Holter ECG recordings showed non-sustained VT (nsVT). In 3 cases, electrophysiological studies were performed before

Table 1. Clinical and demographic characteristics of the study group

\begin{tabular}{|l|c|}
\multicolumn{1}{|c|}{ Characteristic } & Value \\
\hline Number of patients & 20 \\
\hline Median age of implantation [years] & $15.6(3.8-17.7)$ \\
\hline Gender & $8 \mathrm{~F}(40 \%) / 12 \mathrm{M} \mathrm{(60 \% )}$ \\
\hline Body weight at initial implantation [kg] & $52.1 \pm 18.6$ \\
\hline $\begin{array}{l}\text { Indications for ICD implantation } \\
\text { primary/secondary }\end{array}$ & $6(30 \%) / 14(70 \%)$ \\
\hline Mean follow-up period [years] & $6.5 \pm 4.8$ \\
\hline Deaths & $3(15 \%)$ \\
\hline Heart transplantation & $1(5 \%)$ \\
\hline
\end{tabular}

F-female; M - male; ICD - implantable cardioverter-defibrillator. the implantation procedure due unknown causes of SCA. Cardiac magnetic resonance imaging (MRI) was performed in 4 patients: 2 with CMP and 2 after resuscitated SCA. In 2 of these patients, there were no abnormalities; in one patient, a diagnosis of non-compact left ventricle (NCLV) was confirmed; in the other, non-ischemic dilated cardiomyopathy (DCM) was eventually diagnosed.

\section{Anti-arrhythmic therapy}

Before ICD implantation, 14 children (70\%) were on AA medication, and after implantation, all 20 children (100\%) were. The most common therapy was beta-blockade (nadolol, metoprolol), either alone or in combination with class III AA drugs (amiodaron, sotalol), as shown in Tables 2 and 3. The optimal treatment for heart failure (HF) according to current guidelines and recommendations was used before ICD implantation in all the children with CMP. ${ }^{12,16}$

Table 2. Clinical data, indications for ICD implantation, therapy, and outcomes in terms of gender

\begin{tabular}{|c|c|c|c|}
\hline Variable & Female & Male & $p$-value \\
\hline Number of patients & $8(40 \%)$ & $12(60 \%)$ & 0.371 \\
\hline Age at $1^{\text {st }}$ intervention [years] & 16.2 & 16.4 & 0.905 \\
\hline $\begin{array}{l}\text { ICD indication } \\
\text { primary } \\
\text { secondary }\end{array}$ & $\begin{array}{l}6(75 \%) \\
2(25 \%)\end{array}$ & $\begin{array}{c}2(17 \%) \\
10(83 \%)\end{array}$ & 0.009 \\
\hline $\begin{array}{l}\text { Diagnosis } \\
\text { PED } \\
\text { CMP } \\
\text { CHD }\end{array}$ & $\begin{array}{l}3(38 \%) \\
5(63 \%) \\
0(0 \%)\end{array}$ & $\begin{array}{l}6(50 \%) \\
4(33 \%) \\
2(17 \%)\end{array}$ & 0.300 \\
\hline $\begin{array}{l}\text { Symptoms } \\
\text { TLOC } \\
\text { palpitations } \\
\text { asymptomatic }\end{array}$ & $\begin{array}{l}2(25 \%) \\
2(25 \%) \\
4(50 \%)\end{array}$ & $\begin{array}{l}3(25 \%) \\
0(0 \%) \\
9(75 \%)\end{array}$ & 0.049 \\
\hline $\begin{array}{l}\text { Pharmacotherapy } \\
\text { before ICD implantation } \\
\text { post ICD implantation }\end{array}$ & $\begin{array}{c}8(100 \%) \\
\text { all }\end{array}$ & $\begin{array}{c}6(50 \%) \\
\text { all }\end{array}$ & 0.017 \\
\hline $\begin{array}{l}\text { Pharmacotherapy } \\
\text { II } \\
\text { III } \\
\text { AA therapy + HF }\end{array}$ & $\begin{array}{l}3(38 \%) \\
1(13 \%) \\
4(50 \%)\end{array}$ & $\begin{array}{l}6(50 \%) \\
0(0 \%) \\
6(50 \%)\end{array}$ & 0.435 \\
\hline Deaths & $1(13 \%)$ & $2(17 \%)$ & 0.761 \\
\hline HTX & $1(13 \%)$ & $0(0 \%)$ & 0.209 \\
\hline $\begin{array}{l}\text { ICD interventions } \\
\text { Al } \\
\text { IA } \\
\text { both } \\
\text { none }\end{array}$ & $\begin{array}{l}3(38 \%) \\
1(12 \%) \\
1(12 \%) \\
3(38 \%)\end{array}$ & $\begin{array}{c}5(42 \%) \\
1(8 \%) \\
0(0 \%) \\
6(50 \%)\end{array}$ & 0.621 \\
\hline Time to first Al [days] & 361 & 163 & 1.000 \\
\hline Time to first IA [days] & 1,664 & 350 & 0.667 \\
\hline $\begin{array}{l}\text { Therapy effectiveness } \\
\text { effective } \\
\text { non-effective }\end{array}$ & $\begin{array}{l}4(50 \%) \\
4(50 \%)\end{array}$ & $\begin{array}{l}5(42 \%) \\
7(58 \%)\end{array}$ & 0.714 \\
\hline
\end{tabular}

ICD - implantable cardioverter-defibrillators; CMP - cardiomyopathy; CHD - congenital heart defect; PED - primary electrical disease; TLOC - transient loss of consciousness; AA therapy - antiarrhythmic therapy; HF - heart failure; HTX - heart transplantation; Al - appropriate interventions; IA - inappropriate interventions. 


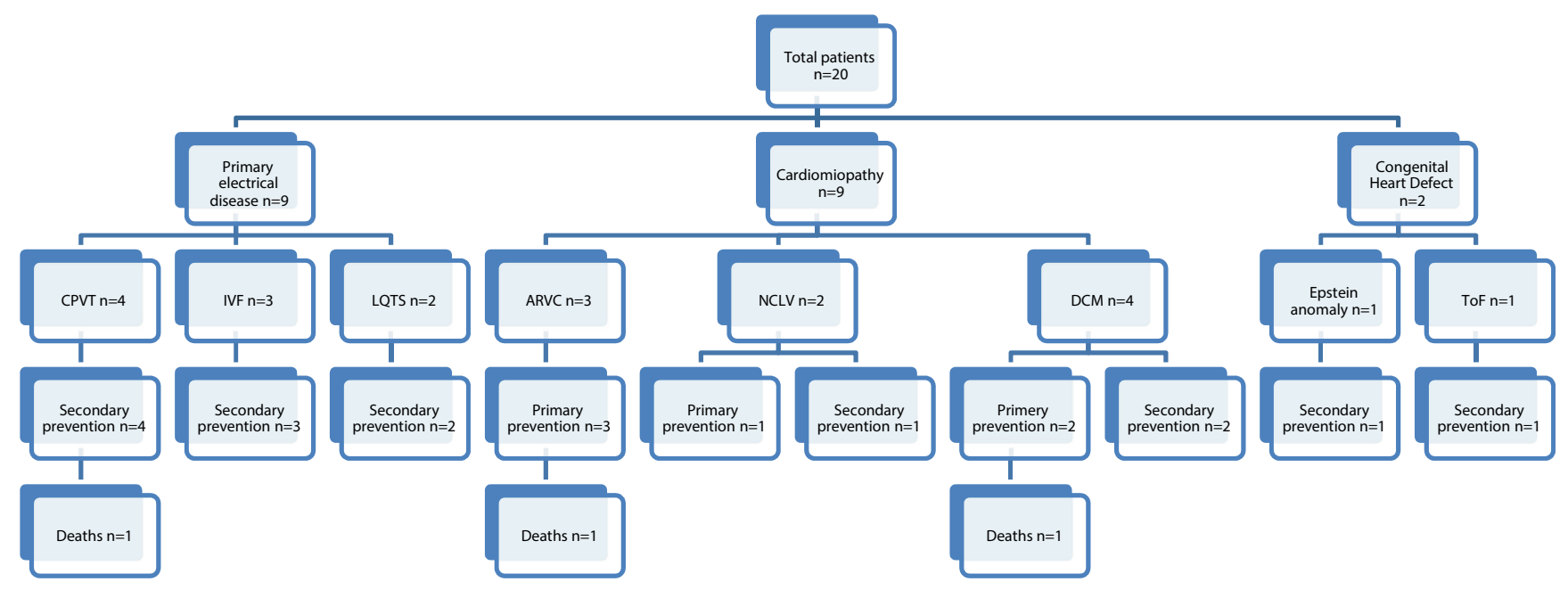

Fig. 1. Indications for implantable cardioverter-defibrillator (ICD) implantation and cardiovascular disease (CVD) in the study group

\section{Technical aspects of ICD implantation}

All the initial procedures were performed under general anesthesia. The most common initial approach for ICD implantation was transvenous (used in 19 children). Among the implanted systems there were 14 single-chamber and 5 dual-chamber ICDs. A biventricular device (cardiac resynchronization) was placed in 1 patient. Single-coil leads were placed in 17 children and dual-coil leads in 3 .

In 3 children, a single-chamber ICD was placed in the abdominal region and an active-fixation ICD lead was simultaneously implanted through the subclavian vein. The incision was made parallel to the linea and then to the tendon of the rectus abdominalis, and the ICD was placed under that muscle in a subrectus pocket. Then, the ICD lead was tunneled subcutaneously to the subclavian region and was placed through the cephalic vein in the apex of the right ventricle. The ICD "active can" was connected to the lead (or leads), all electrical parameters were measured again and a defibrillation test was performed.

A defibrillation threshold test (DFT) was performed according to current guidelines. The mean DFT result at primary implantation was $15 \mathrm{~J}$ (range: 6-20 J). The VF detection duration was programmed initially between "18 out of 24 " and " 75 out of 100 " based on the reason for ICD implantation. The initial $\mathrm{R}$ wave amplitude was $8.9 \pm 4 \mathrm{mV}$. In our only patient with an epicardial lead, the DFT was $10 \mathrm{~J}$. All shocks were programmed to the maximum energy output of the devices.

There were no acute intraprocedural or early post-procedural complications at the initial ICD implantations.

\section{The effects of gender}

To check whether gender had any impact, we examined potential differences between females and males in this study (Table 2). Loss of consciousness or family history were significantly more frequent reasons for establishing the diagnosis and qualification for SCD prevention in boys $(\mathrm{p}=0.042)$ than in girls, while palpitations were significantly more frequent reasons among girls. Girls were more likely to receive pharmacotherapy prior to ICD implantation $(\mathrm{p}=0.017)$ and were more often treated in primary prevention $(\mathrm{p}=0.009)$. No differences ( $p>0.05$ ) between the sexes as to the effectiveness of treatment with ICD or the effectiveness of pharmacotherapy were found.

\section{Primary vs secondary prevention of SCD}

Patients were also divided into groups depending on the type of indication for ICD implantation - primary vs secondary prevention (Table 3 ), and our comparative

Table 3. Clinical data, etiology, arrhythmia occurrence, EF, and results of the treatment used in the study group in terms of ICD implantation for secondary vs primary prevention

\begin{tabular}{|l|c|c|c|}
\hline \multicolumn{1}{|c|}{ Prevention of SCD } & Primary & Secondary & p-value \\
\hline Number of patients & 8 & 12 & 0.371 \\
\hline Sex & & & \\
F & $2(17 \%)$ & $6(75 \%)$ & 0.009 \\
\hline Diagnosis & $10(83 \%)$ & $2(25 \%)$ & \\
CHD & & & \\
CMP & $0(0 \%)$ & $2(17 \%)$ & 0.007 \\
PED & $7(88 \%)$ & $2(17 \%)$ & \\
\hline EF & $1(13 \%)$ & $8(67 \%)$ & \\
\hline$>50 \%$ & & & \\
$<50 \%$ & $2(25 \%)$ & $12(100 \%)$ & 0.001 \\
\hline Pharmacotherapy & $6(75 \%)$ & $0(0 \%)$ & \\
I & & & \\
II & 0 & 0 & \\
III & $1(13 \%)$ & $8(67 \%)$ & 0.043 \\
AA therapy+ HF & $1(13 \%)$ & $0(0 \%)$ & \\
\hline Therapy effectiveness & $6(75 \%)$ & $4(33 \%)$ & \\
effective & $6(75 \%)$ & $3(25 \%)$ & 0.028 \\
non-effective & $2(25 \%)$ & $9(75 \%)$ & \\
\hline
\end{tabular}

ICD - implantable cardioverter-defibrillators; SCD - sudden cardiac death; CMP - cardiomyopathy; CHD - congenital heart defect; PED - primary electrical disease; EF - ejection fraction; AA therapy - anti-arrhythmic therapy; HF - heart failure. 
analysis showed several statistically significant differences between these groups. As mentioned earlier, ICDs were implanted in girls for primary prevention significantly more often than for secondary $(p=0.009)$. Also, there were significant differences $(\mathrm{p}<0.001)$ between the reasons for reporting to a cardiologist among the patients treated in primary prevention (with no history of SAC) compared to those in secondary prevention (with a history of resuscitated SAC). Additionally, in primary prevention, patients with CMP were treated more often compared to patients with normal heart anatomy $(\mathrm{p}=0.009)$ or those with CHD (tetralogy of Fallot, Ebstein's anomaly) ( $p=0.039$ ).

Patients treated for primary prevention had significantly higher ( $\mathrm{p}=0.011$ ) incidence of nonspecific intraventricular conduction delays (Fig. 2) compared to those treated for secondary prevention, who more often had right bundle branch blocks (RBBBs) or incomplete right bundle branch blocks (IRBBBs). ${ }^{17}$ One child had a left bundle branch block (LBBB). Ventricular arrhythmias of at least 3 morphologies $(\mathrm{p}<0.001)$ and documented episodes of VF were more frequent among the patients qualified for secondary prevention ( $\mathrm{p}=0.006)$. Patients with reduced left ventral contractility (LVEF < 50\%) more frequently had ICDs implanted as primary prevention $(\mathrm{p}<0.001)$.

If the primary cause of the referral to a cardiologist was TLOC, treatment (ICD and pharmacotherapy combined) was more effective ( $p=0.035)$; if the reason for the referral was family history, it was ineffective $(\mathrm{p}<0.001)$. Other reasons for referrals were not found to affect the effectiveness of the combined treatment. The type of prevention (primary or secondary) was also a factor influencing the effectiveness of the treatment $(p=0.028)$.

It was also found that in secondary prevention, arrhythmia was more complex: nsVT/VT/VF, as opposed to VPB in primary prevention).

\section{Appropriate and inappropriate device discharge}

An analysis of ICD intervention in terms of AI and IA or a lack of intervention was carried out (Table 4). There were 126 ICD interventions in 11 patients (55\%): 102 (81\%)
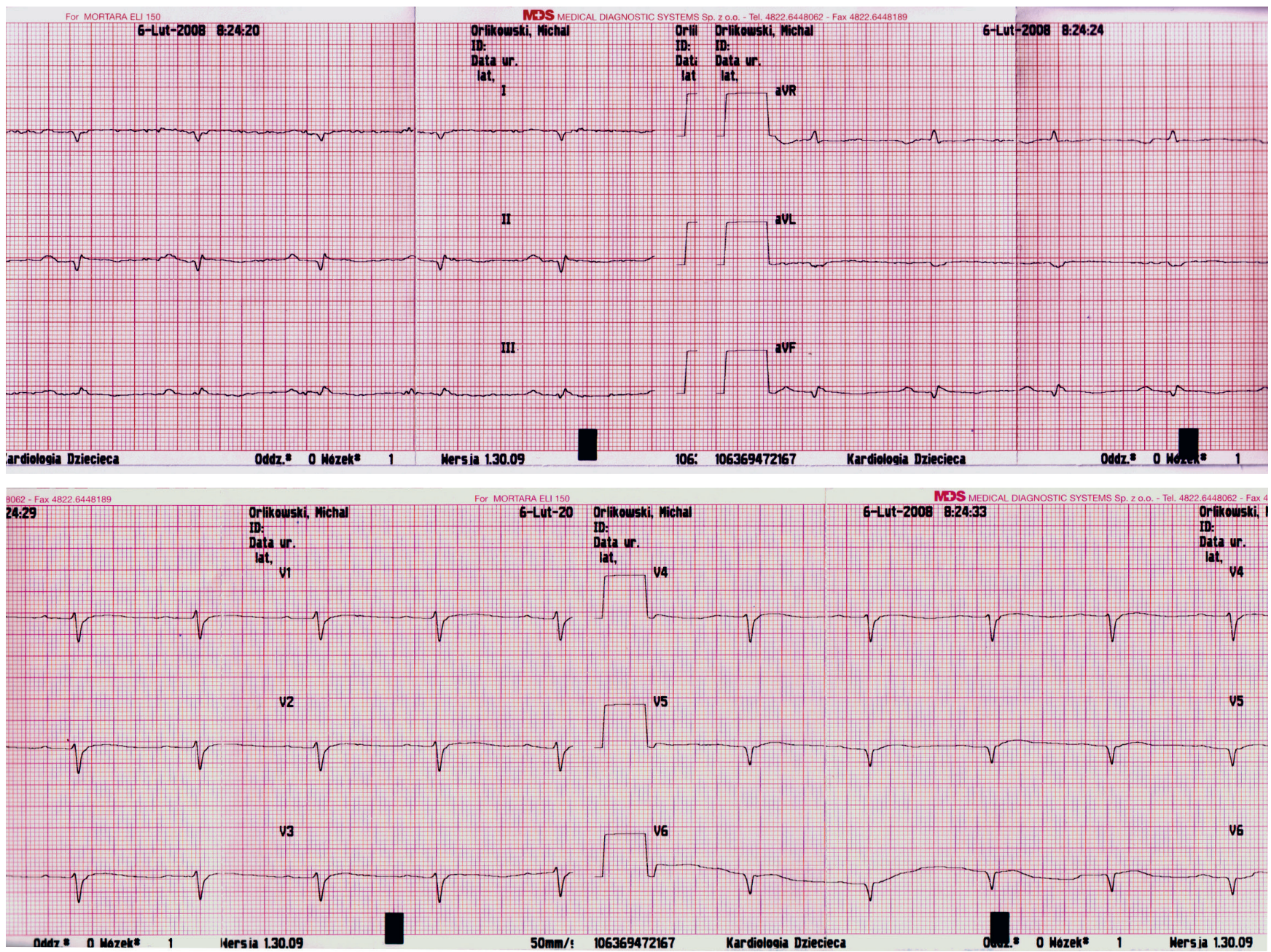

Fig. 2. ECG demonstrates intraventricular non-specific conduction block in a 6 -year old patient qualified for the primary implantable cardioverterdefibrillator (ICD) implantation due to dilated cardiomyopathy (DCM). Interventricular conduction delay (IVCD) is determined on the based on the current recommendation ${ }^{17}$ 
Table 4. Appropriate and inappropriate device discharges

\begin{tabular}{|c|c|c|c|c|c|}
\hline Variable & $\begin{array}{l}\text { Total number of patients having } \\
\text { any interventions }\end{array}$ & $\mathrm{Al}$ & $\mathrm{IA}$ & $\begin{array}{l}\text { Both interventions (AI } \\
\qquad \& \mid A)\end{array}$ & $p$-value \\
\hline Number of patients & 11 & 8 & 2 & 1 & 0.020 \\
\hline $\begin{array}{l}\text { Sex } \\
\text { female } \\
\text { male }\end{array}$ & $\begin{array}{l}5(63 \%) \\
6(50 \%)\end{array}$ & $\begin{array}{l}3(38 \%) \\
5(42 \%)\end{array}$ & $\begin{array}{l}1(13 \%) \\
1(8 \%)\end{array}$ & $\begin{array}{l}1(13 \%) \\
0(0 \%)\end{array}$ & 0.621 \\
\hline $\begin{array}{l}\text { ICD indication } \\
\text { primary } \\
\text { secondary }\end{array}$ & $\begin{array}{l}5(63 \%) \\
6(49 \%)\end{array}$ & $\begin{array}{l}4(50 \%) \\
4(33 \%)\end{array}$ & $\begin{array}{l}1(13 \%) \\
1(8 \%)\end{array}$ & $\begin{array}{l}0(0 \%) \\
1(8 \%)\end{array}$ & 0.632 \\
\hline $\begin{array}{l}\text { Diagnosis } \\
\text { PED } \\
\text { CMP } \\
\text { CHD }\end{array}$ & $\begin{array}{l}4(44 \%) \\
5(55 \%) \\
2(100 \%)\end{array}$ & $\begin{array}{l}2(22 \%) \\
4(44 \%) \\
2(100 \%)\end{array}$ & $\begin{array}{l}1(11 \%) \\
1(11 \%) \\
0(0 \%)\end{array}$ & $\begin{array}{l}1(11 \%) \\
0(0 \%) \\
0(0 \%)\end{array}$ & 0.528 \\
\hline $\begin{array}{l}\text { Time to the } 1^{\text {st }} \text { intervention } \\
\text { [days] (range) }\end{array}$ & $\begin{array}{c}350 \\
(6-2,412)\end{array}$ & $\begin{array}{c}163 \\
(6-2,412)\end{array}$ & $\begin{array}{c}637 \\
(350-2,691)\end{array}$ & 82 & \\
\hline
\end{tabular}

ICD - implantable cardioverter-defibrillator; PED - primary electrical disease; CMP - cardiomyopathy; CHD - congenital heart defect; AA therapy - antiarrhythmic therapy; AI - appropriate interventions; IA - inappropriate interventions. ICD Model: Marquis VR 7230
Serial Number: PKD609671S

\section{May 19, 2006 16:16:31 9967 Software Version 4.0 Copyright Medronic. Inc. 2002 \\ VT/VF Episode \#5 Report}

\begin{tabular}{lllllll}
\hline ID\# & Date/Time & Type & V. Cycle & Last Rx & Success & Duration \\
\hline 5 & May 05 10:13:25 & VF & $370 \mathrm{~ms}$ & VF Rx 6 & No & $2.8 \mathrm{~min}$
\end{tabular}

Fig. 3. The record of electrogram (EGM) from implantable cardioverter-defibrillator (ICD) demonstrates inappropriate shocks (IA) due to oversensing of T-wave
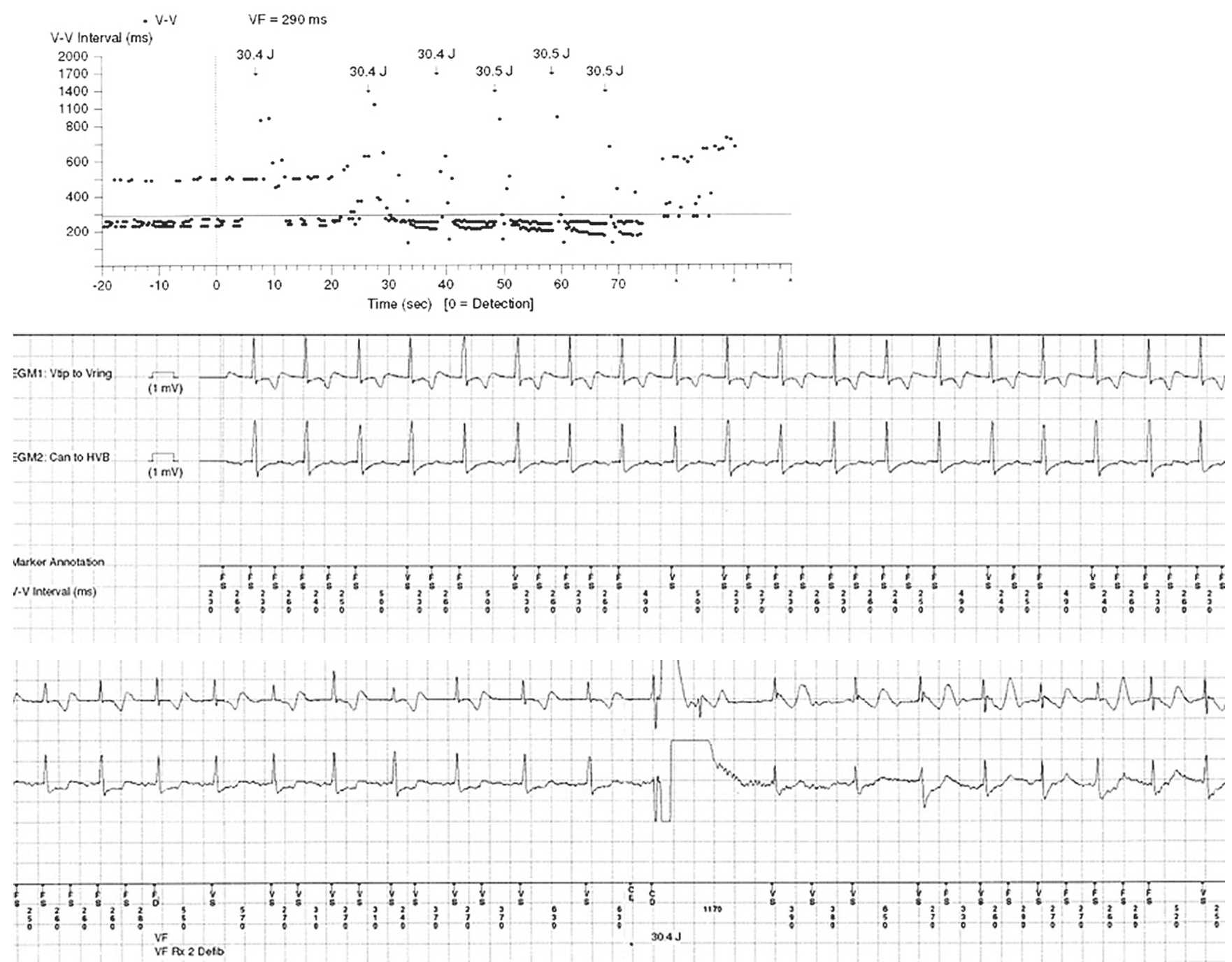
AIs in 8 children (40\%) and $22(18.2 \%)$ IA in 2 patients (10\%); 1 teenager had 1 AI (0.8\%) and 1 IA (0.8\%) intervention (Fig. 3). The rate of IA due to non-optimal programming of the device was $5 \%$; oversensing of the $\mathrm{T}$-wave caused 10\%; pace/sense lead dislocations were the cause of $5 \%$; and HV lead failure (LF) caused $10 \%$ of IAs. There were no interventions at all in 9 patients (45\%). The median time before the $1^{\text {st }}$ intervention (of any kind) was 350 days (range: 6-2,412 days).

\section{ICD-system-related complications and actions taken to solve them}

During the follow-up period, 1 girl with arrhythmogenic right ventricle CMP (ARVC) underwent heart transplantation 6 months after ICD implantation, at the age of 17 . A patient with an ICD implanted for primary prevention of SCD gave a birth to a healthy neonate 7 years after the ICD implantation. None of the patients in our study group had the ICD removed permanently, and there were no infections of the implanted ICD systems during the follow-up period. In 2 cases, remote monitoring was used; the devices documented atrial fibrillation in 1 case and nsVT in the other. In both cases, the pharmacological AA therapy was then modified.

During the follow-up period 3 of the patients died. The $1^{\text {st }}$ patient was an adolescent with catecholaminergic polymorphic ventricle tachycardia (CPVT), who received his ICD in 2000 (the $1^{\text {st }}$ patient in our study) at the age of 15; he died 3 years after ICD implantation due to therapy-resistant VF. He was on maximal pharmacotherapy at that time (a combination of class II and class III AA drugs). The ICD in this case was a Medtronic Micro Jewel II, model 7223 Cx (Medtronic plc, Dublin, Ireland), implanted in a left abdominal pocket with the lead tunneled from the infraclavicular region to the pocket. The implant defibrillation threshold (DFT) was $15 \mathrm{~J}$ measured using a biphasic waveform. The DFT was rechecked within 2.5 months after implantation and remained unchanged. The lead impedance at implant was $45 \Omega$. The $1^{\text {st }}$ AI was delivered just 1 week after implantation. The device was programmed for the VT and VF zones, and 34 J shocks. At the time of the patient's therapy-resistant VF, the VF detection rate was $240 \mathrm{bpm}$, the detection number count was 24 out of 32, and the VT zone was $200 \mathrm{bpm}$ and 75 out of 100 .

The $2^{\text {nd }}$ patient that died, a girl with DCM who received her ICD as a bridge to a heart transplant at the age of 16 , died 6 months after implantation due to therapy-resistant VF (an electrical storm).

The $3^{\text {rd }}$ patient that died, a boy with ARVC, underwent ICD implantation at the age of 6 as a bridge to a transplant. He died 4 months after implantation due to $\mathrm{HF}$ resistant to pharmacotherapy. The $1^{\text {st }} \mathrm{AI}$ in this case (ATP due to FVT) was documented 56 days post implantation.

Data concerning ICD-system related complications and actions taken to solve them is presented in Table 5. Six patients (30\%) experienced LF, 2 patients (10\%) experienced failures of pace/sense leads and 5 patients (25\%) experienced failures of high-voltage (HV) leads. In 2 patients, more than $1 \mathrm{LF}$ took place. In total, 7 re-interventions were performed from 0.1 to 11.3 years (median: 7.4 years) from the initial system implantation; 6 of them were related to malfunctions of Sprint Fidelis HV leads (Medtronic plc). In the per-procedure analysis, the overall freedom from $\mathrm{HV}$ lead replacement was 90\%, 80\% and 57\% during 1,5 and 10 years of observation, respectively.

During the follow-up period, the whole ICD system was replaced in 4 cases using Cook lead extraction tools (Cook Medical LLC, Bloomington, USA).

Table 5. Complications due to HV lead dislocation or failure

\begin{tabular}{|c|c|c|c|c|}
\hline \multirow{2}{*}{$\begin{array}{l}\text { Patient } \\
\text { ID }\end{array}$} & \multirow{2}{*}{$\begin{array}{l}\text { Year of initial } \\
\text { surgery }\end{array}$} & \multicolumn{3}{|r|}{ Re-intervention } \\
\hline & & $\begin{array}{l}\text { Time to } \\
\text { [years] }\end{array}$ & Cause & Procedure performed \\
\hline 2 & 2005 & 11.3 & $\begin{array}{l}\text { HV LF - Sprint Fidelis (6949) } \\
\text { (high threshold on FU visit) }\end{array}$ & $\begin{array}{l}\text { Extraction with Cook, new HV Lead implanted } \\
\text { (Biotronic Linox Smart S65) }\end{array}$ \\
\hline 3 & 2005 & $\begin{array}{l}0.1 \\
10.4\end{array}$ & $\begin{array}{l}\text { HV lead dislocation - Sprint } \\
\quad \text { Fidelis (6949) } \\
\text { HV LF - Sprint Fidelis (6949) } \\
\text { (high threshold on FU visit) }\end{array}$ & $\begin{array}{c}\text { Extraction with traction, new HV lead implanted } \\
\text { (Medtronic 6949) } \\
\text { Extraction with Cook of old leads, new leads implanted } \\
\text { (Biotronic Protego ProMRI and Medtronic CapSureFix Novus } 5076-52 \mathrm{~cm} \text { ) }\end{array}$ \\
\hline 4 & $\begin{array}{l}2005 \\
2006\end{array}$ & $\begin{array}{l}0.5 \\
9.7\end{array}$ & $\begin{array}{l}\text { HV lead dislocation - Sprint } \\
\quad \text { Fidelis (6949) } \\
\text { HV LF - Sprint Fidelis (6949) } \\
\text { (high threshold on FU visit) }\end{array}$ & $\begin{array}{l}\text { Extraction with traction, new HV lead implanted } \\
\text { (Medtronic 6949) } \\
\text { Extraction with Cook, new HV lead implanted (Biotronic Linox S65) } \\
\text { Complication: embolisation of subclavian vein }\end{array}$ \\
\hline 9 & 2007 & 1.8 & $\begin{array}{c}\text { HV LF - Sprint Fidelis (6931) } \\
\text { (IA shocks due to HV lead } \\
\text { fracture) }\end{array}$ & Extraction with traction, new HV lead implanted (Biotronic Linox S65) \\
\hline 12 & 2008 & 7.4 & $\begin{array}{l}\text { HV LF - Biotronic Linox S65 } \\
\text { (high threshold on FU visit) }\end{array}$ & $\begin{array}{l}\text { Extraction with Cook Evolution, implantation of new leads } \\
\text { (Biotronic Linox and Medtronic } 5076-52 \mathrm{~cm} \text { ) }\end{array}$ \\
\hline
\end{tabular}

HV - high voltage; LF - lead failure; IA - inappropriate intervention. 


\section{Discussion}

The present data from a long-term single-center registry of children and adolescents undergoing ICD implantation offers one of the longest follow-up periods under the same supervisor in the same center in the available literature. Furthermore, this patient population presents a remarkable incidence of appropriate therapy delivery and displays the long-term course of children with ICDs in detail, particularly regarding device complications.

\section{Effects of gender}

We divided our study cohort according to gender. The groups did not differ significantly in terms of age or diagnosis (both organic heart disease and electrical pathology); however, in a more detailed statistical analysis, there were several significant differences between the groups. This may suggest that girls pay more attention to the feeling of heart "palpitations", while boys get medical care only after incidents of unconsciousness. As a secondary result of this difference, girls were more likely to receive pharmacotherapy prior to ICD implantation and were more often treated for primary prevention. In the literature, we did not find any studies that analyzed this aspect. Interestingly, no differences between the sexes were identified in our study in terms of the effectiveness of either ICD treatment or pharmacotherapy. There are only few available studies concerning this subject. ${ }^{18}$ In their study, Sears et al. investigated differences between male and female pediatric ICD patients in terms of quality of life (QOL), and their conclusion was that "the observed differences in lower psychosocial, physical, and cardiacspecific QOL between female and male patients suggest that female patients feel particularly limited across these domains of functioning". ${ }^{19}$

\section{Secondary vs primary prevention of SCD}

Implantable cardioverter-defibrillator implantation techniques have been simplified considerably in recent years thanks to significant reductions in the dimensions of modern generators and the use of transvenous leads. ${ }^{9,10,13,14,20}$ In the past, ICD implantation was mainly performed for secondary prevention of SCD, but nowadays ICDs are often implanted for primary prevention, although this is still a field of great controversy. ${ }^{4,8,13,21,22}$ We studied several factors to determine the effectiveness of primary vs secondary prevention of SCD.

With regard to pharmacotherapy, the 2 analyzed groups differed significantly. Those treated for primary prevention were more likely to receive pharmacotherapy before implantation $(\mathrm{p}=0.017)$, and they more often received AA drugs (class III) or combination therapy: class III and optimal HF treatment according to current guidelines and recommendations. The patients in the secondary prevention group primarily had $\beta$-blocker therapy. ${ }^{23}$ This was mainly related to differences in the underlying diseases.

Comparing the groups in which the treatment was assessed as effective or ineffective, it was found that they differed in terms of certain characteristics. Firstly, in the group characterized by ineffective treatment, patients with CMP were more frequent, while in the effective treatment group, more patients with congenital malformations or PED with normal heart anatomy were found $(p=0.025)$. To some extent, this observation might have been influenced by the guidelines and how the patients were qualified for treatment.

Secondly, the type of prevention (primary or secondary) was a factor determining the effectiveness of the treatment $(\mathrm{p}=0.028)$. It was revealed that in secondary prevention of SCD, complex arrhythmia was diagnosed more frequently than in primary prevention.

The statistical analysis also showed that ventricular arrhythmia morphology was a factor determining the effectiveness of ICD interventions and combination therapy $(p=0.004)$. The treatment used was significantly less effective in the presence of 2 ventricular beat morphologies (both LBBB and RBBB). In addition, reduced LVEF was a significant $(\mathrm{p}=0.002)$ parameter determining overall treatment efficacy (pharmacological treatment and ICD interventions). Apart from the above, no other factors related to the effectiveness of therapy were found.

\section{Appropriate and inappropriate device therapy}

Implantable cardioverter-defibrillator shocks delivered for reasons other than life-threatening ventricular arrhythmias, known as IA, occur frequently in ICD-equipped patients. ${ }^{1,24-26}$ Pediatric patients and patients with CHD have a particularly high rate of IAs, with the largest studies reporting up to $20 \%$ of patients receiving them, mainly due to higher heart rates in younger patients, a higher risk of lead malfunction due to more active lifestyles and longer follow-up periods. ${ }^{26-30}$ That is why in our center, since the very first case, we have been programming devices individually, based on the patients' individual characteristics, in order to achieve the best results. ${ }^{1,7,31}$

In our study, 3 patients (15\%) suffered from a total of 23 IAs. Specifically, the rate of IAs due to non-optimal programming of the device was $5 \%$; due to $\mathrm{T}$-wave oversensing $10 \%$; due to pace/sense lead dislocations $5 \%$; and due to $\mathrm{HV}$ LF in $10 \%$ of the incidents. Some of the children had more than 1 cause of IA intervention. Some of the children had more than 1 cause of IA. Using the experience in the present study, we were able to demonstrate that individualized ICD programming, such as higher VT detection rates, detection restricted to the VF zone and longer detection intervals, was probably crucial to keeping the rate of IAs low. ${ }^{10,24,32}$

There is more and more evidence that defibrillator shocks can cause myocardial damage, and the shocks have 
been associated with increased mortality. ${ }^{5,33}$ In the pediatric population, reductions in the number of IA and the associated significant reductions in total IA energy delivered to the myocardium may have resulted in diminished myocardial damage and lower mortality in this particular group of patients. The time period prior to the $1^{\text {st }}$ intervention (AI or IA) was 350 days (range: 6-2,412 days); and it did not correlate with any other of the factors studied; in particular, it was not an independent variable of SCD/SCA.

There were 3 deaths during the present study, all of them in the pioneer era of ICD implantation in children, and detailed subgroup analyses of the relationship between device programming and death have limited power. The findings from randomized trials and our own experience support the ongoing evolution of ICD therapy for primary prevention, in parallel with programming approaches reducing inappropriate therapies and increasing survival among patients with ICDs. ${ }^{10,24}$

\section{ICD-system-related complications and actions taken to solve them}

In 1980, Mirowski published an article about the use of ICDs in patients who had undergone successful resuscitation. ${ }^{34}$ The external cardioverter-defibrillator had been a recognized therapeutic tool for decades, but Mirowski was the first to introduce a fully automatic implantable device, comparable to implantable pacemakers.

The $1^{\text {st }}$ report of ICD implantation in a young patient was published in 1988 by Kral et al. ${ }^{14}$ The $1^{\text {st }}$ ICD implantation in a teenager in our center was performed in 2000. In that young teenager with CPVT, we initially programmed the VF detection rate at $240 \mathrm{bpm}$ and the detection counter at 24 out of 32; the VT zone was from $200 \mathrm{bpm}$. Unfortunately, despite optimal pharmacotherapy, therapy-resistant VF occurred. Because of the recurrent VF, despite repeated shocks, we decided to delay the therapy, switching the detection counter to 75 out of 100 . That was meant to reduce the number of shocks and thus to reduce adrenergic stimulation, which may be effective in some patients. Nonetheless, the arrhythmia could not be suppressed in any way, and the patient died. Since that time, we have programmed the detection counter to 75 out of 100 in all 3 of our subsequent patients with CPVT. None of them experienced electrical storms during their follow-up periods (which lasted 13, 12 and 10 years, respectively). One of them, who is subject to regular cardiological follow-up every 6-12 months, now has a five-year old daughter.

Lead-related complications are the most common adverse events during follow-up. ${ }^{8,10,27}$ Lewandowski et al. reported a $21 \%$ rate of complications requiring surgical intervention. ${ }^{26}$ In our study, considering all 23 IA (18.2\%), more than half of them took place because of LF (17/23; 74\%). Despite the significant technological progress that has been made in recent years in the field, ICD implantation is still more complicated in children than in adults..$^{8,9,35-38}$ There are no dedicated leads for small vessel diameters. Existing ICD devices are not adapted to the small body surface and weight of a pediatric patient, and abdominal implantation of the power generator may be necessary. ${ }^{20,28,29,39,40}$ Lead failure is an important issue to all physicians taking care of patients with ICDs because of its serious consequences. Unfortunately, its incidence is difficult to determine, due to several factors. During the past 2 decades, several recalled leads have appeared on the market. ${ }^{37}$ The recalled Medtronic Sprint Fidelis series serves as an example of conductor and insulation failure. Recently, there was a recall of SJM devices. According to data from the literature, the failure rate for Sprint Fidelis leads is about 20\% at 10 years. Our management of children with functioning recalled leads was very individual. In all cases, we focused on intensifying the monitoring plan, and followed the programming strategy recommended by the manufacturer. ${ }^{37}$ In cases of patients with externalized cables, but with no electrical abnormalities, we reprogrammed the devices, and performed extraction with the insertion of a new ICD lead during a planned device exchange. Since 2010 lead extraction has been performed at our center with surgical backup.

\section{Study limitations}

This study has several limitations. The study design was a retrospective cohort analysis, and underestimation of LF cannot be excluded. The indications for ICD implantation are more heterogenic than in an adult population, where ischemic origins predominate. The programming details of anti-tachycardia therapy could not be systematically assessed, as it was very heterogeneous over the long study period and frequently changed even in the same individual. Patients presenting with abnormal lead parameters underwent standard radiography to assess whether any structural damage was present. The exact mechanisms of LF could not be confirmed in every case. Based on clinical decisions whether to extract or abandon the lead, not all the leads were visually examined, and were not available for a returned product analysis by the manufacturer.

\section{Conclusions}

The ICD implantation indications in children are more heterogeneous than in the adult population. In the pediatric population undergoing ICD implantation, the treatment strategy is influenced by gender. The rate of IAs in our group of pediatric patients was low. Rigorous pharmacotherapy and individual ICD programming seemed to be of paramount importance. Lead malfunctions were the most prevalent complications observed, and most of them were related to Sprint Fidelis leads. 


\section{ORCID iDs}

Joanna Kwiatkowska (1) https://orcid.org/0000-0001-9760-1977 Szymon Budrejko (1) https://orcid.org/0000-0002-5254-0813 Marek Wasicionek (10) https://orcid.org/0000-0003-1818-5878 Jarosław Meyer-Szary (1) https://orcid.org/0000-0001-8791-5497 Andrzej Lubiński (1) https://orcid.org/0000-0003-2779-0041 Maciej Kempa (D) https://orcid.org/0000-0002-3472-2883

\section{References}

1. Chang PM, Powell BD, Jones PW, Carter N, Hayes DL, Saxon LA. Implantable cardioverter defibrillator programming characteristics, shocked rhythms, and survival among patients under thirty years of age. J Cardiovasc Electrophysiol. 2016;27(10):1183-1190. doi:10.1111/jce.13038

2. Wilkoff BL, Fauchier L, Stiles MK, et al. Erratum to '2015 HRS/EHRA/ APHRS/SOLAECE expert consensus statement on optimal implantable cardioverter-defibrillator programming and testing'. J Arrhythmia. 2016;32(5):441-442. doi:10.1016/j.joa.2016.08.001

3. Migowski A, Ribeiro AL, Carvalho MS, et al. Seven years of use of implantable cardioverter-defibrillator therapies: A nationwide population-based assessment of their effectiveness in real clinical settings. BMC Cardiovasc Disord. 2015;15:22. doi:10.1186/s12872-015-0016-2

4. Priori SG, Blomström-Lundqvist C. 2015 European Society of Cardiology Guidelines for the management of patients with ventricular arrhythmias and the prevention of sudden cardiac death summarized by co-chairs. Eur Heart J. 2015;36(41):2757-2759. doi:10.1093/ eurheartj/ehv445

5. Santharam S, Hudsmith L, Thorne S, Clift P, Marshall H, De Bono J. Long-term follow-up of implantable cardioverter-defibrillators in adult congenital heart disease patients: Indications and outcomes. Europace. 2017;19(3):407-413. doi:10.1093/europace/euw076

6. Blom NA. Implantable cardioverter-defibrillators in children. Pacing Clin Electrophysiol. 2008;31(Suppl 1):S32-S34. doi:10.1111/j.1540-8159. 2008.00952

7. Cheitlin MD, Conill A, Epstein AE, et al. ACC/AHA Guidelines for Implantation of Cardiac Pacemakers and Antiarrhythmia Devices: A Report of the American College of Cardiology/American Heart Association Task Force on Practice Guidelines (Committee on Pacemaker Implantation). Circultion. 1998;97(13):1325-1335. doi:10.1016/ S0735-1097(98)00024-2

8. Asakai H, Shimizu A, Mitsuhashi T, et al; Members of the Implantable Cardioverter-Defibrillator (ICD) Committee of the Japanese Heart Rhythm Society. Current trends in implantable cardioverter-defibrillator therapy in children: Results from the JCDTR database. Circ J. 2018;83(1):52-55. doi:10.1253/circj.CJ-18-0712

9. Bogush N, Espinosa RE, Cannon BC, et al. Selecting the right defibrillator in the younger patient: Transvenous, epicardial or subcutaneous? Int J Cardiol. 2018;250:133-138. doi:10.1016/j.ijcard.2017.09.213

10. Krause U, Müller MJ, Wilberg Y, et al. Transvenous and non-transvenous implantable cardioverter-defibrillators in children, adolescents, and adults with congenital heart disease: Who is at risk for appropriate and inappropriate shocks? EP Eur. 2018;21(1):106-113. doi:10.1093/ europace/euy219

11. Walsh EP, Cecchin F. Recent advances in pacemaker and implantable defibrillator therapy for young patients. Curr Opin Cardiol. 2004; 19(2):91-96. doi:10.1097/00001573-200403000-00004

12. Adams KF, Baughman KL, Dec WG, et al. Heart Failure Society of America (HFSA) guidelines for management of patients with heart failure caused by left ventricular systolic dysfunction-pharmacological approaches. Pharmacotherapy. 2000;20:495-522.

13. Heersche JHM, Blom NA, Van De Heuvel F, et al. Implantable cardioverter defibrillator therapy for prevention of sudden cardiac death in children in the Netherlands. Pacing Clin Electrophysiol. 2010;33(2): 179-185. doi:10.1111/j.1540-8159.2009.02603

14. Kral MA, Spotnitz HM, Hordof A, Bigger JT, Steinberg JS, Livelli FD. Automatic implantable cardioverter defibrillator implantation for malignant ventricular arrhythmias associated with congential heart disease. Am J Cardiol. 1989;63(1):118-119. doi:10.1016/00029149(89)91093-x

15. Baysa SJA, Olen M, Kanter RJ, Fishberger SB. Defibrillation testing strategies of pediatric and adult congenital electrophysiologists during ICD implantation. Pacing Clin Electrophysiol. 2016;39(8):843-847. doi:10.1111/pace.12896
16. Dickstein K, Cohen-Solal A, Filippatos G, et al; ESC Committee for Practice Guidelines (CPG). ESC Guidelines for the diagnosis and treatment of acute and chronic heart failure 2008: The Task Force for the Diagnosis and Treatment of Acute and Chronic Heart Failure 2008 of the European Society of Cardiology. Developed in collaboration with the Heart Failure Association of the ESC (HFA) and endorsed by the European Society of Intensive Care Medicine (ESICM). Eur Heart J. 2016;29(19):2388-2442. doi:10.1093/eurhearti/ehn309

17. Kamphuis VP, Blom NA, van Zwet EW, et al. Normal values of the ventricular gradient and QRS-T angle, derived from the pediatric electrocardiogram. J Electrocardiol. 2018;51(3):490-495. doi:10.1016/j.electrocard.2018.01.002

18. Chair SY, Lee CK, Choi KC, Sears SF. Quality of life outcomes in Chinese patients with implantable cardioverter defibrillators. Pacing Clin Electrophysiol. 2011;34(7):858-867. doi:10.1111/j.1540-8159.2011.03048

19. Sears SF, Burns JL, Handberg E, Sotile WM, Conti JB. Young at heart: Understanding the unique psychosocial adjustment of young implantable cardioverter defibrillator recipients. Pacing Clin Electrophysiol. 2001;24(7):1113-1117. doi:10.1046/j.1460-9592.2001.01113

20. Berul Cl. Implantable cardioverter-defibrillators in children: Innovation to design a pediatric ICD. J Innov Card Rhythm Manag. 2011;2: 179-185.

21. Maron BJ, Spirito $P$, Ackerman MJ, et al. Prevention of sudden cardiac death with implantable cardioverter: Defibrillators in children and adolescents with hypertrophic cardiomyopathy. J Am Coll Cardiol. 2013;61(14):1527-1535. doi:10.1016/j.jacc.2013.01.037

22. Schinkel AFL. Implantable cardioverter defibrillators in arrhythmogenic right ventricular dysplasia/cardiomyopathy: Patient outcomes, incidence of appropriate and inappropriate interventions, and complications. Circ Arrhythmia Electrophysiol. 2013;6(3):562-568. doi:10. 1161/CIRCEP.113.000392

23. Ciemny S, Kwiatkowska J, Królak T, Kempa M. Nastolatek traci przytomność na ulicy. Folia Cardiol. 2016;11(1):61-65. doi:10.5603/FC.2016. 0008

24. Moss AJ, Schuger C, Beck CA, et al; MADIT-RIT Trial Investigators. Reduction in inappropriate therapy and mortality through ICD programming. NEng/JMed. 2012;367(24):2275-2283. doi:10.1056/NEJMoa 1211107

25. Kriebel T, Ruschewski W, Gonzalez MGY, et al. ICD implantation in infants and small children: The extracardiac technique. Pacing Clin Electrophysiol. 2006;29(12):1319-1325. doi:10.1111/j.1540-8159.2006. 00542

26. Lewandowski M, Sterliński M, Maclg A, et al. Long-term follow-up of children and young adults treated with implantable cardioverter-defibrillator: The authors' own experience with optimal implantable cardioverter-defibrillator programming. Europace. 2010;12(9): 1245-1250. doi:10.1093/europace/euq263

27. Silvetti MS, Saputo FA, Palmieri R, et al. Results of remote follow-up and monitoring in young patients with cardiac implantable electronic devices. Cardiol Young. 2014;26(1):53-60. doi:10.1017/S1047951 114002613

28. Von Bergen NH, Atkins DL, Dick M, et al. Multicenter study of the effectiveness of implantable cardioverter defibrillators in children and young adults with heart disease. Pediatr Cardiol. 2011;32(4):399-405. doi:10.1007/s00246-010-9866-7

29. Dechert BE, Bradley DJ, Serwer GA, Dick M, Lapage MJ. Implantable cardioverter defibrillator outcomes in pediatric and congenital heart disease:Time to system revision. Pacing Clin Electrophysiol. 2016;39(7): 703-708. doi:10.1111/pace.12878

30. Malloy LE, Gingerich J, Olson MD, Atkins DL. Remote monitoring of cardiovascular implantable devices in the pediatric population improves detection of adverse events. Pediatr Cardiol. 2014;35(2) 301-306. doi:10.1007/s00246-013-0774-5

31. Khairy P, Mansour F. Implantable cardioverter-defibrillators in congenital heart disease: 10 programming tips. Hear Rhythm. 2011;8(3): 480-483. doi:10.1016/j.hrthm.2010.10.046

32. Walsh EP. Practical aspects of implantable defibrillator therapy in patients with congenital heart disease. Pacing Clin Electrophysiol. 2008;31(Suppl 1):38-40. doi:10.1111/j.1540-8159.2008.00954

33. Jin BK, Bang JS, Choi EY, et al. Implantable cardioverter defibrillator therapy in pediatric and congenital heart disease patients: A single tertiary center experience in Korea. Korean J Pediatr. 2013;56(3):125-129. doi:10.3345/kjp.2013.56.3.125 
34. Mirowski M, Mower MM, Reid PR. The automatic implantable defibrillator. Am Heart J. 1980;100(6 Pt 2):1089-1092. doi:10.1016/00028703(80)90218-5

35. Bordachar P, Marquié C, Pospiech T, et al. Subcutaneous implantable cardioverter defibrillators in children, young adults and patients with congenital heart disease. Int J Cardiol. 2016;203:251-258. doi:10. 1016/j.ijcard.2015.09.083

36. Garnreiter JM, Pilcher TA, Etheridge SP, Saarel E V. Inappropriate ICD shocks in pediatrics and congenital heart disease patients: Risk factors and programming strategies. Hear Rhythm. 2015;12(5):937-942. doi:10.1016/j.hrthm.2015.01.028
37. Swerdlow CD, Kalahasty G, Ellenbogen KA. Implantable cardiac defibrillator lead failure and management. J Am Coll Cardiol. 2016;67(11): 1358-1368. doi:10.1016/j.jacc.2015.12.067

38. Frommeyer G, Feder S, Bettin M, et al. Long-term single-center experience of defibrillator therapy in children and adolescents. Int J Cardiol. 2018;271:105-108. doi:10.1016/j.ijcard.2018.05.130

39. CzosekRJ,MeganathanK, AndersonJB, KnilansTK,MarinoBS, Heaton PC. Cardiac rhythm devices in the pediatric population: Utilization and complications. Hear Rhythm. 2012;9(2):199-208. doi:10.1016/j.hrthm. 2011.09.004

40. Von Gunten S, Schaer BA, Yap SC, et al. Longevity of implantable cardioverter defibrillators: A comparison among manufacturers and over time. Europace. 2016;18(5):710-717. doi:10.1093/europace/euv296 